\title{
SERANGAN PENGGEREK PADI PUTIH DAN PENAMPILAN AGRONOMIS GALUR-GALUR PADI SAWAH IRIGASI
}

\author{
Suprapto $^{1}$ dan Widyantoro ${ }^{1}$
}

\begin{abstract}
ABTRACT
The white rice borer (Tryporyza innotata Walker) attack and agronomic traits of low land paddy lines. Field trial evaluation on 10 lines/varieties to observe the white rice borer (Tryporyza innotata Walker) attack and agronomic traits was conducted at AIAT Lampung on wet season of 2004. The trial was conducted in endemic white rice borer area in Rejo Basuki, Seputih Raman District, Central Lampung. Experiment was arranged in a Randomized Block Design with four replications. Variables observed were precentage of plants attack, yield at $14 \%$ moisture contents, period of flowering, number of grain, total grain per panicle, number of stem per hill, plants height, maturity, 100 seed weight and vegetative and generative vigors. Results indicated that among the lines/varieties there were significant different on white rice borer incidence. The BP-360e-Mr-79-Pn-2 line showed low incidence of white rice borer, higher number of stem per hill height plant $104.9 \mathrm{~cm}$, total grain per panicle of $5200 \mathrm{~kg}, 1000$ grain weight and good on vegetative and better generative vigor. But no different seed is compared with other lines, the BP-360e-Mr-79-Pn-2 lines showed 49. 9 empty grain per panicle and $80 \%$ mature at 105 days harvested.
\end{abstract}

Key words : Oryza sativa , low land paddy, agronomic traits, tolerance, Tryporyza innotata

\section{PENDAHULUAN}

Dalam usaha menunjang melestarikan swasembada pangan, upaya peningkatan produksi banyak mengalami masalah baik biologis, non biologis dan sosial ekonomi. Kendala usaha peningkatan produksi tersebut tampak pada pertumbuhan produksi pangan pada beberapa tahun terakhir yang mengalami penurunan. Pada tahun 1983 - 1987 laju peningkatan produksi padi mencapai 3,4 \%, kemudian pada tahun 1988 - 1993 laju produksi padi mengalami penuruan menjadi 2,9\% sedangkan pada periode tersebut kebutuhan padi meningkat 3,6 \% dari 40,84 juta ton manjadi 47,02 juta ton (Adjid, 1993). Menurunnya laju produksi padi secara nasional tersebut antara lain disebabkan karena varietas unggul padi sawah irigasi yang dapat ditanam secara luas mulai terbatas, sebagian varietas telah mengalami degradasi genetik peka terhadap hama, penyakit dan produktivitasnya menurun.

Salah satu kendala yang dihadapi dalam melakukan usahatani padi di lahan sawah irigasi antara lain adalah hama penggerek padi putih (Tryporyza innotata Walker) (Lepidoptera, Noctuidae) (Soewito et al., 1993; Soehardjan, 1983) dan penampilan agronomis varietas dan galur padi sawah yang dikembangkan mulai menurun produktivitasnya. Menurut Soewito et al. (1993) galur-galur padi hasil penelitian yang dilepas menjadi varietas unggul yang telah dikembangkan di lapang adalah memiliki sifat - sifat baik antara lain tahan terhadap hama dan penyakit, mempunyai penampilan agronomis baik yaitu hasil tinggi, umur genjah, tanaman relatif pendek serta vigor tanaman dan mutu berasnya baik. Disamping itu varietas padi unggul baru harus dapat beradaptasi pada lahan marginal yang kesuburan tanahnya rendah, $\mathrm{pH}$ rendah, adanya senyawa pirit dan gambut, intrusi air laut, genangan air serta gangguan hama dan penyakit (Suwarno \& Suhartini, 1993; Sugiyono \& Bustaman, 1993).

Dewasa ini telah dilepas beberapa padi unggul yang dapat beradaptasi baik pada lahan sawah irigasi yang berdaya hasil tinggi dan toleran terhadap penggerek padi putih, antara lain adalah varietas Cisadane (Soewito et al., 1993). Cisadane merupakan padi varietas unggul untuk lahan sawah irigasi yang dapat beradaptasi dengan baik di lahan gambut dan sawah pasang surut secara luas (Suwarno \& Suhartini, 1993). Padi sawah irigasi tersebut sampai saat ini di sebagian lahan sawah irigasi potensial di Indonesia masih dapat berkembang cukup baik. Meskipun demikian, penanaman varietas padi yang sama secara luas terus menerus akan dapat menimbulkan kerapuhan genetik (Harahap \& Silitonga, 1988), sehingga varietas padi yang tadinya tahan terhadap hama dan penyakit akan menjadi peka dan penampilan agronomis serta produktivitasnya akan menurun.

Di Lampung telah banyak varietas padi sawah irigasi unggul ditanam petani, seperti misalnya Widas, Ciherang, IR-64, Cilosari, Digul, Way Apo Buru

\footnotetext{
${ }^{1}$ Peneliti Balai Pengkajian Teknologi Pertanian Lampung, Jln. Zainal Abidin Pagaralam, Bandar Lampung
} 
(Arjasa et al., 2004), dan pada tahun 2004 dikembangkan varietas Fatmawati secara luas di beberapa kabupaten. Varietas padi tersebut ternyata tidak seluruhnya toleran terhadap hama penggerek padi putih dan penampilan agronomis serta produksinya tidak semuanya baik. Di beberapa daerah penampilan agronomis dan produksinya kurang menonjol dan bahkan terserang hama dan penyakit. Masalah tersebut muncul antara lain karena sebagian varietas telah beberapa tahun ditanam secara luas. Menurut Harahap dan Silitonga (1988), varietas padi yang telah di tanam secara terus menerus pada areal luas terjadi kerapuhan genetik yang menyebabkan tanaman padi mulai peka terhadap hama dan penyakit serta menurun produksinya. Galur padi sawah irigasi yang relatif toleran terhadap hama penggerek padi putih masih terbatas, salah satu diantaranya adalah galur B10393-Mr-13-1-3 (Suprapto et al., 2002). Sehubungan dengan hal tersebut maka dilakukan penelitian keragaan serangan penggerek batang dan penampilan agronomis galur-galur padi sawah irigasi. Penelitian dimaksudkan untuk memperoleh informasi tentang serangan hama penggerek padi putih (T. innotata ) dan penampilan agronomis galur-galur padi sawah irigasi sebagai bahan pertimbangan dalam usaha mengatasi kendala tersebut di lapang.

\section{METODE PENELITIAN}

Keragaan serangan penggerek batang ( $T$. innotata ) dan penampilan agronomis galur-galur padi sawah irigasi telah diteliti BPTP Lampung pada MK tahun 2004 di daerah endemik serangan penggerek padi putih di desa Rejo Basuki, Kecamatan Seputih Raman, Lampung Tengah. Penelitian dilakukan dengan menggunakan rancangan Acak Kelompok terdiri atas 10 perlakuan dan setiap perlakuan di ulang empat kali. Perlakuan yang diuji terdiri atas delapan galur padi sawah adalah BP-23fPn-1; BP-140f-Mr-Kn-1; BP-205f-Mr-9-1; BP-226fMr-76; BP-355e-Mr-45; BP-360e-Mr-79-Pn-2; BP342b-Mr-1-3; B-10384b-Mr-3-1-2, dan dua varietas padi sebagai pembanding, yaitu varietas Fatmawati dan Ciherang. Ukuran petak 4 x $5 \mathrm{~m}$, jumlah bibit perumpun 2-3 bibit, ditanam dengan tapin tanam berjajar (legowo 2:1) dengan jarak tanam 20 x 10 × 40 $\mathrm{cm}$, umur bibit 21-25 hari. Penanaman dilakukan pada tanggal 13 bulan Mei 2004. Pemupukan pertama pada saat tanam dilakukan dengan menggunakan $150 \mathrm{~kg}$ Urea + 100 kg SP-36 + 100 kg KCL per hektar dan pemupukan kedua dilakukan pada waktu tanaman padi berumur 45 hari setelah tanam dengan dosis $100 \mathrm{~kg}$ urea per hektar.

Pengamatan dilakukan terhadap keragaan serangan penggerek batang ( $T$. innotata) dan penampilan agronomis galur-galur dan varietas yang diuji. Pengamatan dilakukan pada 10 rumpun tanaman contoh yang ditentukan secara acak dari rumpun tanaman di bagian tengah petak yang berjarak 5 baris dari pinggir batas petak. Pengamatan serangan penggerek batang ( $T$. innotata) dilakukan terhadap jumlah tanaman yang mati terserang penggrek padi putih per rumpun yang ditandai dengan adanya gerekan hama $T$. innotata pada batang padi yang mati. Pengamatan serangan penggerek batang dilakukan pada umur 35, 80, dan 100 hari. Sedangkan pengamatan penampilan agronomis dilakukan terhadap tinggi tanaman, jumlah malai produktif per rumpun, panjang malai, gabah isi dan persentase gabah hampa per malai, bobot gabah per 3 rumpun, bobot (seed size) gabah 1000 butir, kadar air $14 \%$, umur masak $80 \%$ dan vigor tanaman pada fase vegetatif dan generatif. Pengamatan tinggi tanaman, jumlah malai produktif per rumpun dilakukan pada umur 100 hari. Pengamatan panjang malai, gabah isi dan persentase gabah hampa per malai dilakukan pada 20 malai yang ditentukan secara acak dari 10 rumpun tanaman contoh. Pengamatan bobot gabah per 3 rumpun ditentukan dari 10 rumpun tanaman contoh. Sedangkan pengamatan bobot gabah 1000 butir ditentukan secara acak dari hasil gabah kering panen setiap petak. Pengamatan hasil gabah kadar air $14 \%$, umur masak $80 \%$ dan vigor tanaman pada fase vegetatif dan generatif dilakukan pada setiap petak perlakuan ukuran $4 \times 5 \mathrm{~m}$. Pengamatan vigor secara skoring dengan skala skor 1 - 9 mulai dari sangat baik skor 1 , baik skor 3 , sedang skor 5 , jelek skor 7 dan sangat jelek skor 9 . Analisis data dilakukan dengan uji Duncan pada tingkat beda nyata $5 \%$.

\section{HASIL DAN PEMBAHASAN}

Hasil penelitian terhadap delapan galur dan dua varietas padi sawah irigasi menunjukkan bahwa penggerek padi putih ditemukan merusak pada semua galur dan varietas padi yang diuji dengan tingkat kerusakan yang beragam. Kerusakaan tanaman padi akibat serangan hama penggerek padi putih pada tanaman padi umur 35 hari berkisar antara 0,0 - 14,3\% tanaman tiap rumpun dan tampak galur BP-360e-Mr-79-Pn-2, BP-23f-Pn-1 dan BP-205f-Mr9-1 kerusakan tanaman lebih rendah dari pada galur 
B-10384b-Mr-3-1-2, BP-342b-Mr-1-3 dan BP-226fMr-76, varietas Fatmawati, Ciherang dan galur lainnya. Pada umur 80 hari serangan hama penggerek padi putih masih cukup beragam, berkisar antara 4,1 - 28,3 \% tanaman tiap rumpun dan tampak galur BP-140f-Mr-Kn-1 dan BP-360e-Mr-79-Pn-2 tingkat serangannya tergolong lebih rendah, hanya 4,1-4,3 \% tanaman tiap rumpun, sementara galur lainnya berkisar 5,8 - 28,3 \% tanaman tiap rumpun. Selanjutnya pada umur 100 hari serangan hama penggerek padi putih pada tiap perlakuan masih cukup beragam, yaitu berkisar 2,0 - 25,9 \% tanaman tiap rumpun dan tampak galur BP-360e-Mr-79-Pn-2 dan varietas Fatmawati tingkat serangannya tergolong lebih rendah, hanya 2,0 - 2,2 \% tanaman tiap rumpun, sementara galur lainnya berkisar 5,8 - 25,9 \% tanaman tiap rumpun. Dalam hal tingkat serangan penggerek padi putih, diantara galur BP-360e-Mr-79Pn-2, BP-23f-Pn-1, BP-205f-Mr-9-1 dan varietas Fatmawati yang tampak relatif stabil dengan tingkat serangan rendah adalah galur BP-360e-Mr-79-Pn-2 dengan tingkat serangan hanya 2,2-4,3 \% (Tabel 1).

Galur BP-360e-Mr-79-Pn-2 disamping mempunyai tingkat serangan penggerek padi putih rendah juga mempunyai jumlah malai per rumpun tidak berbeda dengan varietas padi Fatmawati dan Ciherang sebagai pembanding. Tinggi tanaman galur padi BP-360e-Mr-79-Pn-2 tergolong pendek hanya 104,98 cm tidak berbeda dengan varietas padi Fatmawati dan Ciherang sebagai pembanding (Tabel 1). Hal tersebut selaras dengan program pemuliaan yang dilakukan untuk memperoleh varietas padi unggul yang mempunyai persyaratan sifat-sifat baik sesuai yang diinginkan antara lain disamping tingkat serangan hama dan penyakit rendah, juga memiliki hasil tinggi, umur genjah, tanaman relatif pendek dan mutu berasnya baik (Soewito et al., 1993).

Galur BP-360e-Mr-79-Pn-2 mempunyai gabah isi per malai sebanyak 110,00 butir tidak berbeda dengan varietas Ciherang dan galur lainnya dengan jumlah malai antara 93 - 102 butir, kecuali dibanding dengan varietas Fatmawati dan galur BP-342b-Mr-1-3 yang menunjukkan jumlah gabah isi per malai lebih tinggi yaitu 149 - 172 butir. Galur BP-360e-Mr-79Pn-2 mempunyai jumlah gabah hampa per malai tergolong rendah hanya 49,9 butir per malai tidak berbeda dengan varietas Ciherang dan galur lainnya kecuali dibanding dengan varietas Fatmawati yang menunjukkan gabah hampa paling tinggi yaitu 75,69 butir per malai ( Tabel 2).

Bobot gabah per 3 rumpun galur BP-360e-Mr79-Pn-2 adalah 110,28 g. Hal ini tergolong tinggi meskipun tidak berbeda dengan varietas Fatmawati, Ciherang, dan galur lainya. Produksi gabah kering bersih kadar air $14 \%$ galur BP-360e-Mr-79-Pn-2 mencapai $5.200 \mathrm{~kg}$ per hektar lebih tinggi dari galur BP-140f-Mr-Kn-1, BP-205f-Mr-9-1 dan BP-226fMr-76 yang hanya 3.588 - $4.725 \mathrm{~kg}$ per hektar, serta tidak berbeda dengan varietas Fatmawati, Ciherang dan galur lainnya, keculai dengan galur B-10384bMr-3-1-2 yang produksinya mencapai $6.063 \mathrm{~kg}$ per hektar (Tabel 2).

Tebel 1. Keragaan serangan penggerek padi putih, jumlah anakan produksi dan tinggi tanaman padi

\begin{tabular}{|c|c|c|c|c|c|c|}
\hline \multirow[t]{2}{*}{ No } & \multirow[t]{2}{*}{$\begin{array}{l}\text { Perlakuan varietas } \\
\text { /Galur padi }\end{array}$} & \multicolumn{3}{|c|}{$\begin{array}{c}\text { Serangan penggrek padi putih (\%) batang } \\
\text { per rumpun pada umur (hari) }\end{array}$} & \multirow[t]{2}{*}{$\begin{array}{l}\text { Tinggi tanaman } \\
\text { (cm) }\end{array}$} & \multirow[t]{2}{*}{$\begin{array}{c}\text { Jumlah malai } \\
\text { per rumpun }\end{array}$} \\
\hline & & 35 hari & 80 hari & 100 hari & & \\
\hline 1 & BP-23f-Pn-1 & 0,0 & 5,8 & 5,8 & $102,10 \mathrm{bc}$ & $10,20 \mathrm{bc}$ \\
\hline 2 & BP-140f-Mr-Kn-1 & 3,0 & 4,1 & 11,2 & $97,68 \mathrm{c}$ & $9,73 \mathrm{~cd}$ \\
\hline 3 & BP-205f-Mr-9-1 & 0,0 & 19,4 & 12,1 & 101,64 bc & $12,25 \mathrm{a}$ \\
\hline 4 & BP-226f-Mr-76 & 12,7 & 10,8 & 14,7 & $104,13 \mathrm{ab}$ & $10,08 \mathrm{bc}$ \\
\hline 5 & BP-355e-Mr-45 & 2,2 & 9,8 & 9,1 & $104,78 \mathrm{ab}$ & 13,15 a \\
\hline 6 & BP-360e-Mr-79-Pn-2 & 0,0 & 4,3 & 2,2 & $104,98 a b$ & $9,08 \mathrm{~cd}$ \\
\hline 7 & BP-342b-Mr-1-3 & 14,0 & 17,4 & 11,6 & 101,48 bc & $8,58 \mathrm{~cd}$ \\
\hline 8 & B-10384b-Mr-3-1-2 & 14,3 & 28,3 & 25,9 & $109,52 \mathrm{a}$ & $8,00 \mathrm{~d}$ \\
\hline 9 & Fatmawati & 3,2 & 27,5 & 2,0 & $103,43 \mathrm{~b}$ & $9,75 \mathrm{~cd}$ \\
\hline 10 & Ciherang & 9,5 & 16,2 & 11,1 & $105,03 \mathrm{ab}$ & $9,83 \mathrm{~cd}$ \\
\hline & KK $(\mathrm{CV}) \%$ & & & & 3,30 & 14,50 \\
\hline & Nilai F (5\%) & & & & 5,70 & 2,0 \\
\hline
\end{tabular}

Keterangan : Angka selajur yang diikuti huruf yang sama tidak berbeda nyata menurut uji Duncan 5 \%. 
Tabel 2. Keragaan produksi galur dan varietas padi sawah irigasi

\begin{tabular}{|c|c|c|c|c|c|c|}
\hline No & $\begin{array}{l}\text { Perlakuan varietas } \\
\text { /Galur padi }\end{array}$ & $\begin{array}{c}\text { Panjang } \\
\text { malai }(\mathrm{cm})\end{array}$ & $\begin{array}{l}\text { Jmlh gabah } \\
\text { isi per malai }\end{array}$ & $\begin{array}{l}\text { gabah } \\
\text { hampa } \\
\text { (butir) }\end{array}$ & $\begin{array}{c}\text { Hasil gabah } \\
\text { (kg /ha) } \\
\text { ka } 14 \%\end{array}$ & $\begin{array}{c}\text { Bobot gabah } \\
\text { per } 3 \text { rumpun } \\
\text { (g) }\end{array}$ \\
\hline 1 & BP-23f-Pn-1 & 24,95 bc & $96,75 \mathrm{~b}$ & 39,5 bcde & 5425 abc & $90,15 \mathrm{ab}$ \\
\hline 2 & BP-140f-Mr-Kn-1 & 25,63 bc & $97,50 \mathrm{~b}$ & $60,15 \mathrm{ab}$ & 3588 e & $77,73 \mathrm{~b}$ \\
\hline 3 & BP-205f-Mr-9-1 & $24,40 \mathrm{c}$ & $111,75 \mathrm{~b}$ & 24,82de & $4425 \mathrm{~d}$ & $94,55 \mathrm{ab}$ \\
\hline 4 & BP-226f-Mr-76 & $22,05 \mathrm{~d}$ & $99,75 \mathrm{~b}$ & $24,58 \mathrm{e}$ & $4725 \mathrm{~cd}$ & $86,00 \mathrm{~b}$ \\
\hline 5 & BP-355e-Mr-45 & $26,75 \mathrm{~b}$ & $93,25 \mathrm{~b}$ & 28,85cde & $5800 \mathrm{ab}$ & $104,45 \mathrm{ab}$ \\
\hline 6 & BP-360e-Mr-79-Pn-2 & 25,33 bc & $110,00 \mathrm{~b}$ & 49,9 bcd & 5200 bc & $110,28 \mathrm{ab}$ \\
\hline 7 & BP-342b-Mr-1-3 & 30,65 a & $172,50 \mathrm{a}$ & $59,40 \mathrm{ab}$ & 5275 bc & $121,70 \mathrm{a}$ \\
\hline 8 & B-10384b-Mr-3-1-2 & $26,68 \mathrm{~b}$ & $102,75 \mathrm{~b}$ & 53,8 abc & 6063 a & $89,73 \mathrm{ab}$ \\
\hline 9 & Fatmawati & $26,88 \mathrm{~b}$ & $149,00 \mathrm{a}$ & 75,69 a & $5850 \mathrm{ab}$ & $99,03 \mathrm{ab}$ \\
\hline 10 & Ciherang & 26,10 bc & $105,25 \mathrm{~b}$ & 36,1 bcde & 5288 bc & $80,58 \mathrm{~b}$ \\
\hline & KK (CV) \% & 4,50 & 14,60 & 35,30 & 7,90 & 21,10 \\
\hline & Nilai F (5\%) & 2,26 & 37,2 & 25,2 & 770 & 34,2 \\
\hline
\end{tabular}

Keterangan : Angka selajur yang diikuti huruf yang sama tidak berbeda nyata menurut uji Duncan $5 \%$.

Tabel 3. Keragaan berat /1000 butir, umur masak dan vigor tiap galur / varietas

\begin{tabular}{clccc}
\hline No & $\begin{array}{c}\text { Perlakuan varietas /Galur } \\
\text { padi }\end{array}$ & $\begin{array}{c}\text { Bobot gabah } \\
1000 \text { butir } \\
\text { (g) }\end{array}$ & $\begin{array}{c}\text { Umur } \\
\text { masak } 80 \% \text { (hari) }\end{array}$ & $\begin{array}{c}\text { Vigor tanaman } \\
\text { vegetatif dan generatif }\end{array}$ \\
\hline 1 & BP-23f-Pn-1 & $29,75 \mathrm{a}$ & $102 \mathrm{a}$ & $3 \mathrm{a}$ \\
2 & BP-140f-Mr-Kn-1 & $30,25 \mathrm{a}$ & $108 \mathrm{~b}$ & $3 \mathrm{a}$ \\
3 & BP-205f-Mr-9-1 & $29,00 \mathrm{a}$ & $102 \mathrm{a}$ & $3 \mathrm{a}$ \\
4 & BP-226f-Mr-76 & $30,00 \mathrm{a}$ & $100 \mathrm{a}$ & $3 \mathrm{a}$ \\
5 & BP-355e-Mr-45 & $30,00 \mathrm{a}$ & $105 \mathrm{ab}$ & $3 \mathrm{a}$ \\
6 & BP-360e-Mr-79-Pn-2 & $30,25 \mathrm{a}$ & $105 \mathrm{ab}$ & $4,5 \mathrm{a}$ \\
7 & BP-342b-Mr-1-3 & $30,25 \mathrm{a}$ & $102 \mathrm{a}$ & $4,5 \mathrm{a}$ \\
8 & B-10384b-Mr-3-1-2 & $27,25 \mathrm{a}$ & $100 \mathrm{a}$ & $4,5 \mathrm{a}$ \\
9 & Fatmawati & $30,00 \mathrm{a}$ & $105 \mathrm{ab}$ & $3 \mathrm{a}$ \\
10 & Ciherang & $29,50 \mathrm{a}$ & $100 \mathrm{a}$ & $3 \mathrm{a}$ \\
\hline & KK (CV) \% & 6,60 & 10,12 & 13,2 \\
& Nilai F (5\%) & 4,2 & 5,4 & 2,0 \\
\hline
\end{tabular}

Keterangan : Angka selajur yang diikuti huruf yang sama tidak berbeda nyata menurut uji Duncan $5 \%$. 
Galur BP-360e-Mr-79-Pn-2 mempunyai berat 1000 butir gabah sebanyak 30,25 g tergolong tinggi meskipun tidak berbeda dengan varietas Fatmawati, Ciherang dan galur lainnya yang mempunyai berat 1000 butir gabah berkisar 27,25 - 30,25 g (Tabel 3). Vigor vegetatif dan generatif dari 8 galur dan 2 varietas padi sawah irigasi yang diuji menunjukkan nilai baik sampai sedang dan tidak menunjukkan perbedaan antara galur yang diuji dengan varietas Fatmawati dan Ciherang. Salah satu galur yang menunjukkan vigor vegetatif dan generatif sedang dengan nilai 4,5 adalah galur BP-360e-Mr-79-Pn-2 (Tabel 3). Galur BP-360e-Mr-79-Pn-2 mempunyai umur masak 80 \% sekitar 105 hari. Hal ini tidak berbeda dengan varietas Fatmawati, Ciherang, dan galur lainnya yang mulai masak $80 \%$ antara 100 108 hari. Galur BP-360e-Mr-79-Pn-2 dan varietas Fatmawati mempunyai umur masak $80 \%$ tergolong sedang dibanding galur BP-140f-Mr-Kn-1 (108 hari) dan varietas Ciherang 100 hari (Tabel 3).

\section{SIMPULAN}

Hasil penelitian keragaan lapang 8 galur dan 2 varietas padi sawah irigasi terhadap penggerek padi putih (Tryporiza innotata Walker) menunjukkan bahwa hama ini ditemukan merusak pada semua galur dan varietas padi yang diuji dengan tingkat kerusakan beragam. Kerusakaan tanaman padi pada umur 35 hari antara 0,0 - 14,3\% batang per rumpun, pada umur 80 hari antara 4,1 - 28,3 \% batang tiap rumpun dan pada umur 100 hari antara 2,0 - 25,9\% tanaman tiap rumpun. Galur BP-360e-Mr-79-Pn-2 mempunyai tingkat serangan penggerek padi putih paling rendah dibandingkan dengan varietas dan galur padi lainnya. Galur BP-360e-Mr-79-Pn-2 disamping mempunyai tingkat serangan penggerek padi putih paling rendah juga mempunyai beberapa keunggulan dan kekurangan. Beberapa keunggulannya antara lain, bobot gabah per 3 rumpun relatif tinggi yaitu 110,28 gram, jumlah gabah isi per malai 110 butir relatif banyak, tanaman tergolong pendek $(104,98 \mathrm{~cm})$. Produksi gabah kering ka $14 \%$ relatif tinggi (5.200 kg) tidak berbeda dengan varietas Fatmawati dan Ciherang, serta vigor fase vegetatif dan generatif sedang. Sedangkan beberapa kekurangan galur BP360e-Mr-79-Pn-2 antara lain mempunyai gabah hampa 49, 9 butir per malai, buah masak $80 \%$ pada umur 105 hari.

\section{DAFTAR PUSTAKA}

Adjid, D.A. 1993. Kebijaksanaan Swasembada dan Ketahanan Pangan. Kinerja Penelitian Tanaman Pangan. Buku 1. Kebijaksanaan dan Hasil Utama Penelitian. Prosiding Simposium Penelitian Tanaman Pangan III. Jakarta/ Bogor 23-25 Agustus 1993. Pusat Penelitian dan Pengembangan Tanaman Pangan. Badan Litbang Pertanian. Hlm. 50 - 64.

Ardjasa, W. S., Suprapto \& B. Sudaryanto. 2004. Komponen eknologi unggulan usahatani padi sawah irigasi di Lampung. Kebijakan Perberasan dan Inovasi Teknologi Padi. Pusat Penelitian dan Pengembangan Tanaman Pangan. Badan Litbang Pertanian. Hlm. 653 $-666$.

Harahap, Z \& T.S. Silitonga. 1988. Breeding for resistance against major pests and desease of rice. In. A.H. Zakri (ed) Plant Breeding and Genetic Enginering. Sabrao.

Soehardjan, M. 1983. Dinamika Populasi Penggerek Kuning Padi (Tryporyza incertulas Walker) (Pyralidae, Lepidoptera). Direktorat Pembinaan Penelitian dan Pengabdian Pada Masyarakat. Dikti. Departemen Pendidikan dan Kebudayaan.

Soewito, T., Z. Harahap \& Suwarno. 1993. Perbaikan Varietas Padi Sawah Mendukung Pelestarian Swasembada Beras. Kinerja Penelitian Tanaman Pangan. Buku 2. Prosiding Simposium Penelitian Tanaman Pangan III. Jakarta/ Bogor 23-25 Agustus 1993. Pusat Penelitian dan Pengembangan Tanaman Pangan. Badan Litbang Pertanian. Hlm. 398 $-411$.

Sugiono, M \& M. Bustamam .1993. Pemuliaan dan Biologi Molekuler. Kinerja Penelitian Tanaman Pangan. Buku 2. Prosiding Simposium Penelitian Tanaman Pangan III. Jakarta/ Bogor 23-25 Agustus 1993. Pusat Penelitian dan Pengembangan Tanaman Pangan. Badan Litbang Pertanian. Hlm. 347 $-361$. 
Suprapto, W. S. Ardjasa \& B. Sudaryanto. 2002. Uji toleransi lapang beberapa galur padi sawah irigasi terhadap penggerek padi putih (Tryporiza innotata Walker). Jurnal Agrotropika. 7 (2) : 27-31.
Suwarno \& T. Suhartini. 1993. Perbaikan Varietas Padi untuk Menunjang Usahatani di Lahan Pasang Surut dan Lebak. Kinerja Penelitian Tanaman Pangan. Buku 2. Prosiding Simposium Penelitian Tanaman Pangan III. Jakarta/ Bogor 23-25 Agustus 1993. Pusat Penelitian dan Pengembangan Tanaman Pangan. Badan Litbang Pertanian. Hlm. 429 $-436$. 